\title{
The Structure of Emotional Support Networks in Families Affected by Lynch Syndrome
}

Christopher Steven Marcum, Ph.D.1

Dawn Lea, Ph.D.1

Dina Eliezer, Ph.D. 1

Donald W. Hadley, M.S., C.G.C. 2

Laura M. Koehly, Ph.D.1*

(“Action Editor: Thomas Valente")

1 Social and Behavioral Research Branch, National Human Genome Research Institute, National Institutes of Health, Bethesda MD; 2 Medical Genetics Branch, National Human Genome Research Institute, National Institutes of Health, Bethesda, MD

${ }^{*}$ Corresponding Author: 31 Center Drive, B31/B1B54, Bethesda, MD, USA; koehlyl@mail.nih.gov

Author Contributions:

Dr. Marcum prepared the data, derived the hypotheses, ran the analyses, and wrote the paper.

Dr. Eliezer derived the hypotheses and assisted with writing the paper and running preliminary analyses

Dr. Lea assisted with the writing of the paper.

Mr. Hadley designed, administered, and conducted the original cohort study.

Dr. Koehly designed the study, collected the network data, derived the hypotheses, and wrote the paper.

Declarations: This research approved by the IRB of the National Institutes of Health. Funding supported by NIH ZIA HG200335 (Laura M Koehly, PI). The authors have no conflicts of interest to report. 


\section{The Structure of Emotional Support Networks in Families Affected by Lynch Syndrome}

Keywords: Communal Coping, Genetic Testing, Lynch Syndrome, Social Networks, Emotional Support

\section{Abstract}

Genetic risk is particularly salient for families and testing for genetic conditions is necessarily a family level process. Thus, risk for genetic disease represents a collective stressor shared by family members. According to communal coping theory, families may adapt to such risk vis-a-vis interpersonal exchange of support resources. We propose that communal coping is operationalized through the pattern of supportive relationships observed between family members. While past research has examined support exchange of family members who received genetic testing, the roles of family members who declined testing, or were not otherwise at risk for disease, have not been fully examined. In this study, we take a social network perspective to map communal coping mechanisms to their underlying social interactions and include those who declined testing or were not at risk for Lynch Syndrome. Specifically, we examine the exchange of emotional support resources in families at risk of Lynch Syndrome, a dominantly inherited cancer susceptibility syndrome. Our results show that emotional support resources depend on the testing-status of individual family members and are not limited to the bounds of the family. Network members from within and outside the family system are an important coping resource in this patient population. This work illustrates how social network approaches can be used to test structural hypotheses related to communal coping within a broader system and identifies structural features that characterize coping processes in families affected by Lynch Syndrome.

\section{Introduction}

Genetic risk is particularly salient for families affected by inherited disease and members often mobilize to collectively cope with each other's risk or diagnoses (Koehly, 2017). As such, families often activate interpersonal processes to facilitate adaptation processes that can be understood through the lens of communal coping theory (Afifi, 2015; Lyons, 1998; Schwarz, 2014). Communal coping posits that group members appraise stressors as a shared problem and, together, they mobilize adaptive resources 
to address the problem. Coping processes often involve the exchange of interpersonal resources, such as information, tangible assistance, and emotional support, among group members. Family members at risk of inherited diseases may be particularly likely to engage in communal coping. For example, disseminating information about disease diagnoses or genetic test results is necessary for the development of shared appraisals of risk; collective strategies that address this shared risk may include encouraging uptake of genetic services or engagement in medical screening (Ersig, et al., 2009; Palmquist, et al., 2010). Moreover, members experience distress and worry about their own or others' disease risk and diagnoses suggesting that the exchange of emotional support between family members is also important (Koehly, et al., 2008).

Previous work on communal coping has not fully considered how such interpersonal processes are mapped structurally within the system of individuals coping together. To address these gaps, we take a social network approach. We examine the structural characteristics of familial emotional support networks among individuals who received or declined genetic testing for, or were not-at-risk of, Lynch syndrome (LS); a dominantly inherited cancer susceptibility syndrome. Based on communal coping theory, we hypothesize that families affected by LS will exchange social support amongst each other and have shared support partners, and that these patterns of support will vary depending on differences in testing-status among family members. Although some research has examined social support among those receiving genetic services, it is unknown whether those who decline genetic testing or those who are notat-risk of LS will engage similarly in the communal coping process as those who uptake genetic services. To that end, we evaluate both the direct and indirect provision of emotional support within families based on genetic testing-status. With such an approach, we more precisely map the core principles of communal coping theory onto their interpersonal mechanisms and evaluate whether individual level characteristics might shape such processes.

\section{Background}

\section{Lynch syndrome}

Lynch syndrome (LS) is a dominantly inherited cancer susceptibility syndrome caused by inactivating mutations in one of four mismatch repair genes (Lynch et al., 2009) or due to germline deletions in the EPCAM gene (Kloor et al., 2009). LS is characterized by a high penetrance and early onset of cancer, with development of associated cancers at an earlier age than those at population-based risk (Jasperson et al., 2010). The two most common cancers associated with LS are endometrial and colorectal cancer (Weissman et al., 2012). Carriers of such gene mutations also have higher 
lifetime risk for other cancers including: ovarian, bowel, upper urinary tract, central nervous system, biliary tract, and sebaceous gland cancers (Watson et al., 2008; Weissman et al., 2012).

With such a heterogenous disease risk profile, LS represents a significant source of economic, social, and emotional burden to individuals, families, and society. While genetic screening on a population level is not economically feasible due to the relative rarity of the disease (Hirlekar et al., 2016), families with a history of LS benefit from early screening and genetic services that universal testing of such families may bring (Hampel, 2016).

Testing for LS-associated mutations can potentially identify individuals and families genetically predisposed to developing cancer. Such testing became available in the mid-1990s when causative mutations were first identified (Boland \& Lynch, 2013). Contemporary clinical protocols recommend genetic services to patients who meet specific guidelines including: a family history meeting Amsterdam/Bethesda criteria (Giardiello et al., 2014), an associated LS cancer with microsatellite instability (Umar et al., 2004), or a close relative with an identified LS-associated mutation (Syngal et al., 2015). Testing is generally completed through a cascading process, wherein the first person to test within the family informs and refers into genetic services their first-degree relatives (FDRs) who are at $50 \%$ risk of inheriting the mutation. Referred family members found to carry their family's LS-associated mutation then inform and refer their FDRs in for genetic services and so on, with cascading referral and testing through the family pedigree (Hadley et al., 2003).

Family members undergoing genetic testing for LS have a responsibility to inform relatives of their increased cancer risk (Bartuma et al., 2012; Pentz et al., 2005) and, successful referral to genetic services necessarily involves members communicating about their test results (Leenen et al., 2016). Yet, up to $50 \%$ of at-risk relatives are not successfully referred into genetic services (Sharaf et al., 2013). One barrier to cascadetesting lies in members' non-disclosure of genetic test results; reasons for which include concerns about limited understanding of results, causing worry, lack of interpersonal closeness, or interpersonal conflicts (Aktan-Collan et al., 2011; Gaff et al., 2005; Mesters et al., 2005).

\section{Family systems and genetic risk}

While the risk of developing conditions associated with genetic susceptibility most directly affects biological relatives, the burden of knowledge, prevention, and support, often falls on other family members regardless of biological relatedness (Koehly et al., 2003). For example, spouses may play key roles in disseminating information to their at- 
risk children, providing support as genetic services are considered, and encouraging engagement in risk-reducing or early detection behaviors (Zajdel et al., 2018).

Research to date has focused on the psychological impact of genetic risk notification, effects on family and interpersonal relationships, and factors that may influence options (e.g., screening or surgery) for risk-reduction (Burton et al., 2012; Voorwinden \& Jaspers, 2016). There are few examples that consider the interpersonal landscape in families affected by LS (Ashida et al., 2011; Ersig et al., 2011; Ishii, et al., 2011). The majority of this literature has focused on the perspectives of individuals who received genetic services and has not considered the context when genetic services is chosen by some, but not all, family members. Due to the mixture of biological and non-biological kin that comprise families, family members may fall into three categories when genetic testing is indicated: whether or not individuals become informed about risk through genetics education and counseling, family members may consent to testing (i.e., "testers") or may decline testing (i.e., "decliners"), or they may not be offered testing because they are not at increased risk for inheriting the variant in question.

Decisions whether to receive genetic testing have implications for the psychological well-being of family members. Among those who do receive testing, psychological responses vary not only depending on one's own test results, but also the test results of other family members (Eliezer et al., 2014). Moreover, those who receive genetic testing tend to report better psychological outcomes than those who decline testing, even when decliners are making informed decisions following receipt of genetics education and counseling (Aktan-Collan et al., 2000; Loader et al., 2002). Regardless of testing-status, receipt of genetics education and counseling has been found to be correlated with increased perceptions of social support (Gritz et al., 1999), which may suggest that a shared understanding of risk helps to enrich support systems in LS families, and may explain why individuals who have smaller support networks express more cancer worry (Voorwinden \& Jaspers, 2016). Thus, the testing-status of such family members may represent a context for social similarity, solidarity, and empathy to foster emotional support ties between kin. One potential pathway is through the exchange of emotional support processed through communal coping, to which we now turn.

\section{Communal Coping}

Over the past five decades, there has been significant progress in developing theory and an evidence base for characterizing how individuals cope with stressful events. Theories of stress and coping suggest that, when faced with a stressor, individuals first appraise or evaluate the significance of the stressor, consider the situation along with their available coping resources, and then employ coping efforts to regulate or address 
the stressful event (Folkman \& Lazarus, 1980). Such coping efforts may be problemfocused, in that employed strategies are directed at changing the situation, or they may be emotion-focused, in that employed strategies are directed towards changing how one experiences the situation (Glanz et al., 2002). Communal coping evolved from these individual level coping theories, in which efforts to manage stressors are expanded beyond the individual to a more interpersonal context (Lewis et al., 2006). Such an interpersonal perspective is particularly relevant to the context of inherited disease risk in which coping with genetic risk is often a family level process (Koehly et al., 2003; Peterson, 2005).

Grounded in interdependence theory, communal coping can be characterized by several interpersonal mechanisms (Johnson and Johnson, 2005; Rusbult and Lange, 1996). First, family communication about shared genetic risk of disease, whether individual disease diagnoses, family health history information, or genetic test results, provides for the development of shared appraisals of risk. In the context of LS, such informational exchanges can result in family members identifying as a "cancer family" wherein members share an increased cancer risk (Bartuma et al., 2012; Palmquist et al., 2010). In turn, this shared perception of risk can activate interpersonal processes that are problem-focused; that is, aimed at risk reduction, promoting early detection behaviors, or involving disease management. Interpersonal processes that are problemfocused may include referral to genetic services or encouragement of screening behaviors or tangible assistance related to such activities (Ersig et al., 2009). Interpersonal coping efforts may also be emotion-focused with the goal of reducing distress or worry. Emotion-focused processes may include the exchange of emotional support resources (Gritz, et al. 2005; Koehly et al., 2008); such exchanges are the focus of the current manuscript.

Given that communal coping involves interpersonal mechanisms operating at the collective, rather than individual level, patterns of support exchanges between individual family members are important to consider. Previous studies focused on relational outcomes (e.g., family cohesion and support in coping with cancer) that were aggregated to the individual level rather than focusing on the family network as a whole (Hannum et al., 1991; Kuijer, et al., 2000). Other work has considered the microstructure of support involved in communal coping, such as between spouses (Lewis et al., 2006; Zajdel et al., 2017) or through ego-centered vignettes of relationships with their support partners (Afifi et al., 2006; Berg et al., 1998). While not guided by the communal coping model, Power (2017) showed that individual attributes can shape the macrostructure of social support in larger communities. However, no previous study has viewed communal coping from a macrostructural perspective, wherefrom these processes manifest. As a result, there is a clear mismatch between 
communal coping theory-which is about network processes-and the measurement of outcomes at the individual level. By network processes, we mean the generative interactions between individuals that give rise to the structure of social networks. Thus, we can characterize the interpersonal mechanisms involved in communal coping vis-avis social network processes.

\section{Hypotheses: Communal coping as a network process}

Generally, communal coping mechanisms may involve a number of such network processes. In the context of genetic testing for LS, one of the most likely candidates to consider is testing-status homophily. Homophily is characterized as a network process by which social ties form between two individuals who share common characteristics (McPherson et al., 2001). Family members who decide to receive genetic testing (test receivers), in particular, may feel a shared sense of responsibility of knowing their genetic test results and rely on one another for emotional support. Likewise, test decliners may have similar motivations for doing so, and may rely on each other for support given their decision, especially in the face of potential pressure to engage in genetic services among their test-receiving peers (Douglas et al. 2009). As the communal coping process is theorized to imbue a collective identity as a "cancer family", we hypothesize significant positive effects of both testing-status homophily and heterophily on the likelihood of emotionally supportive relationships (H1a). Moreover, sharing common testing status within a family may serve a source of solidarity and support within this process, and thus we hypothesize that the magnitude of the testingstatus homophily effects to exceed those of the testing-status heterophily effects $(\mathrm{H} 1 \mathrm{~b})$, both relative to mixing with individuals who were not-at-risk. That is, family members may be more inclined and equipped to provide support to family members who are in a similar situation regarding their testing-status.

Relatedly, the network process of reciprocity, whereby two individuals mutually support one another, may also occur as families negotiate their shared stressor of LS (Lawrence \& Schigelone, 2002). Reciprocity may take a general form where anyone who provides emotional support to another benefits from receiving mutual support from that same other regardless of their testing-status, or it may be conditional on testing-status homophily or heterophily (e.g. homophilous reciprocity a la Gondal \& McClean (2013)). That is, general reciprocation of support is common within families (Stoller, 1985; Antonucci \& Jackson, 1990): individuals mutually rely on one another as part of most communal coping strategies. However, individuals may be even more inclined to reciprocate support when their underlying motivations for choosing to test for LS mutations-or not-are aligned. Therefore, we hypothesize that reciprocal supportive relationships will be most likely among pairs of actors that share similar testing status $(\mathrm{H} 2)$. 
While homophily and reciprocity are important drivers of interaction between two individuals, communal coping is likely to involve processes that generate larger clustersor cliques (Douglas et al., 2009)- of emotional support partners as well. For instance, transitive relations between triples of family members may result in strong clustering of emotional support (Granovetter, 1973; 1979). More generally, two individuals who share support partners may turn to each other for emotional support. Because the context of emotional support provision as a result of family members coping collectively with the threat of a high risk of cancer is likely one of 'strong ties' (ibid) we would expect the greater the number of such shared partners the more likely two family members would support each other (Mollenhorst et al., 2011). Such clustering of emotional support may take both exogenous (that is, observed outside the family network) and endogenous (that is observed within the family) forms in our data: in the exogenous form, two family members that share many outside support members may be inclined to emotionally support one another $(\mathrm{H} 3 \mathrm{a})$ and in the endogenous form, ties between two family members may be more likely to form when those members share in common other within-family ties $(\mathrm{H} 3 \mathrm{~b})$. These hypotheses are motivated by the notion that communal coping is an adaptive network process whereby family members become increasingly clustered together.

Despite the tendency for close personal networks, such as families, to generate strong clustering of emotional support ties, members of these smaller networks may become over-extended in some cases. It is important to consider, then, how communal coping within families may involve external network members as sources of support and indeed as potential drivers of ties within families. In particular, one strategy that families may adopt to cope with their risk of LS associated cancers, is to distribute the burden of support as much as possible to individuals who are less constrained by the communal stressor while simultaneously maintaining ties within the family. An easily accessible way to accomplish this is for family members to reach out to their own broader personal network members as resources (House et al., 1988). Individuals with more outside support may be less reliant on their family members for their own support, but may also be seen as a well of support from which their family may draw. Therefore, we hypothesize that having a large number of unique exogenous support (NUES) partners will decrease the likelihood of in-ties forming in the network ( $\mathrm{H} 4 \mathrm{a})$. However, individuals identified as having large external support networks may be perceived to serve as wells of emotional support, and as a result we expect that greater NUES increases the likelihood of out-ties forming in the network ( $\mathrm{H} 4 \mathrm{~b})$. For completeness, we additionally include terms that distinguish between NUES who are biologically vs socially related to each interviewed family member though we situate our hypotheses only on the socially related NUES. 
Moreover, we a priori expect that having greater NUES will suppress the overall formation of any ties by test-receivers and decliners relative to those who were not-atrisk for testing (H5). This final hypothesis is motivated by the underlying cognitive and social demands of communal coping: family members who are at elevated biological risk of disease whom have larger outside support sources may have decreased capacity to seek out or be a source of emotional support within the family network. On the other hand, individuals who are not-at-risk are more distal to the primary stressor and therefore more able to buffer these demands.

\section{Methods}

\section{Data}

Data for this study come from a subset of a research cohort of families with an identified pathogenic mutation in one of the genes associated with LS (52 families within the continental United States, our subset is six families); cohort details are published elsewhere (Hadley et al., 2003), however, we recount minor details relevant to the sampling process that have implications on the present study here.

As part of a long-term follow-up assessment of cohort participants, members were invited to participate in an interview assessing interpersonal exchanges with enumerated network members; family members not captured in the original cohort study were eligible for interview and recruited using a snowball sampling approach. This allowed for the inclusion of additional biological relatives and non-biological family members. Such broad recruitment of family members provided the greatest opportunity to study the social contexts surrounding these at-risk families. Participants completed a single telephone interview consisting of closed- and open-ended questions and received gift cards to nationwide retail stores for their participation. A total of 206 individual informants from 33 families completed telephone interviews about their social network systems (family and friends) and the patterns of support within their family. The current paper focuses on the 6 families that had at least two participating family members who received genetic services and two who actively declined genetic services, and at least one member who was not-at-risk of LS to evaluate our hypotheses related to communal coping and network structure. LS-associated mutations were identified in these families between 1997 and 2004 and the network assessments began at least 3 years following mutation confirmation, reflecting the state of support exchange at the time of assessment; network assessments were obtained between 2007 and 2010. 
Family members participating in the interview enumerated their social network members in response to the question: "When I say 'family,' who do you think of? These can be people who are biologically related to you (like your children), people who are related to you but not through biological ties (like your spouse/partner or in-laws), or people who you consider to be family (like very close friends or coworkers)." The 74 interviewed family informants in the present study provided information on a median of 8 others in their respective networks. For each listed individual, detailed demographic information was obtained along with kinship relation to the interviewee. For each enumerated network member, the interviewee was asked to indicate their role in exchanging varying types of social resources. Here, we focus on the emotional support network resulting from responses to: "which members of your family support you emotionally?"

\section{Analysis}

Our outcome is the structure of the emotional support exchanges between family members: the family emotional support network. Exponential random graph models (ERGM) facilitate modeling of both endogenous and exogenous features of the network together with actor attributes (Robins, et al., 2007). We use a special case of ERGMs to evaluate our hypotheses about how individual testing-status may affect the structure of supportive relationships within families. Specifically, because we have more than one family and wish to make inferences at the network level, we employ a pooled-likelihood ERGM facilitated through the use of block-diagonal constraints that prevent the model from evaluating impossible ties between families (Handcock et al., 2017) while pooling information across families for parameter estimation purposes (see also, Figure 1 Panel $\mathrm{B}$ for an illustration of the design). Alternative approaches such as hierarchical logistic regression or generalized estimating equations with family-level random effects do not appropriately model the dependence in the data and we do not have sufficient sample size to employ ERGM based developments in hierarchical modelling (Slaughter \& Koehly, 2016). Thus, we limit our inferences on estimated effects investigating general processes across families, rather than within specific families, per se.

Formally, the model takes the form: $\operatorname{Pr}(Y=y \mid \Theta)=\frac{\exp \left(\Theta^{T} g(y)\right)}{K(\theta)} f(y)$ (Eq.1), where $Y$ is a random graph, $y$ is an observed network, $\Theta$ is a vector of model coefficients, $g(y)$ is a vector of graph features and covariates (see Appendix A for details on each specific model term), $f(y)$ is an indicator function returning family membership (which defines the block-membership), and $K(\Theta)$ is a normalizing constant. We estimate this model using Maximum Likelihood with sampling via Markov Chain Monte Carlo (MCMC).

Our goal is to build a model of the network structure that most closely represents the underlying communal coping mechanisms posited in our hypotheses (with appropriate 
controls). To help summarize the findings related specifically to our hypotheses we provide a supplementary table that maps each hypothesis to their respective model terms together with the expected direction of the coefficient associated with those terms and outcomes (Online Supplement B). We evaluated a number of candidate models through a combination of model selection by Bayesian Information Criteria (BIC), interpretability, and goodness-of-fit via comparison of observed statistics to simulations from the fitted models (as well as conducting convergence and autocorrelation evaluations of the MCMC statistic chains). The final model we selected to present was the one that most accurately facilitated tests of our specific hypotheses (even if it was not the most preferred by BIC). Several alternative specifications are reported in an appendix (Online Supplement C).

\section{Results}

The descriptive statistics of the sample are provided in Table 1. The six family networks were comprised, on average, of about 12 interviewed informants ${ }^{1}$ who were mostly women (65\%). An additional average of about 50 people per network were enumerated by informant family members but were not subsequently interviewed (e.g., they're exogenous). Overall, these emotional support networks were moderately wellconnected with average density of 0.17 (meaning, on average, about $17 \%$ of possible emotional support ties among interviewed network members were present in the network). There was relatively high reciprocity among family informants in the network with an average of $64 \%$ of out-ties being reciprocated by in-ties. On average, each interviewed family member nominated about 2 additional unique emotional supporters that were not part of the family network (about 1 each for biologically related and socially related supporters, respectively). The average number of additional exogenous emotional supporters that were shared by two family members was low, at less than 1. Moreover, the vast majority of ties within these networks were between biological relatives (about $85 \%$ ). About $69 \%$ of exogenous support ties were between biological kin. The plurality of family member informants were test receivers $(47 \%)$ while fewer declined $(21 \%)$. Roughly $32 \%$ of family member informants were not-at-risk of inheriting the LS mutation. The average age of family members interviewed was about 41 , though the average absolute age-difference between all interviewed family members was about 15.

[[Table 1 About Here]]

\footnotetext{
1 The degrees of freedom for the ERGM arise from summing the products of the values and one minus the values in the first row of Table 1, which gives the number of dyads in the block-diagonal constrained network (956).
} 
Figure 1 Panel A plots each of the six family support relation networks, focused on within informant support ties, using the Fructerman-Reingold force-directed algorithm. Here, we refer to this within informant support network as the "family system"; however, the majority of reported emotional support relationships exogeneous to this system are biological family members who were not informants in this study. Triangle-shaped nodes represent test receivers, square-shaped nodes represent test decliners, and pentagon-shaped nodes represent family members who were not-at-risk for receiving genetic testing. The nodes are colored by family membership (which define the support constraint blocks specified by $f(y)$ in Eq. 1 of our model, as illustrated in Panel B). The size of each node is scaled in proportion to the number of exogenous support partners that family member reported having and the width of each edge is scaled in proportion to the number of exogenous supporters each pair of family members with an edge share. Visual inspection of these graphs reveal that, with the exception of Family 4, each emotional support network consists of multiple-components. As well, one can see significant variability in informants seeking exogenous support. Consider, for example, Family 2. One test receiver reports a large number of unique emotional support ties coming from outside the family network as illustrated by the large triangle and no emotional support ties shared within as represented by their isolated position. The two test decliners in this same family, denoted by the squares, report few unique exogenous supports, and while connected to others within the informant network, few shared supports as well. Indeed, shared exogeneous supports among Family 2 informants are primarily reported among member dyads comprised of at least one member receiving genetic testing services.

\section{[[Figure 1 About Here]]}

The results of the final ERGM are reported in Table 2. We find full support for our first hypothesis that test receivers and decliners would engage in emotional support ties based on status homophily and status heterophily $(\mathrm{H} 1 \mathrm{a})$ relative to mixing within and between those not-at-risk. Additionally, our hypothesis that the magnitude of the of the homophily coefficients would be greater than the heterophily coefficients $(\mathrm{H} 1 \mathrm{~b})$ only holds in comparison to decliner to decliner emotional support ties. These results are supported by the large, significant, positive effects for receiver $->$ receiver $(b=1.6608$, $p<0.05)$ and decliner $->$ decliner $(b=2.5289, p<0.01)$ mixing coefficients, and a positive decliner $->$ receiver mixing effect $(b=1.7533, p<0.01)$ (while the receiver->decliner mixing coefficient was not significant). The effects are unidirectional (that is, nonreciprocal) as indicated by the significantly negative homophilous reciprocity coefficient $(b=-2.2789, p<0.01)$ indicating that reciprocity of emotional support is less likely to occur when two individuals share the same testing-status, net of all else. However, there is a 
positive significant effect of baseline reciprocity, which was included as a control $(b=2.584, p<0.001)$; together with the mixing results, this appears to be largely the product of reciprocated heterophilous emotional support ties (likely between those at elevated biological risk and those not-at-risk, given the above). Thus, we do not find support in favor of our second hypothesis $(\mathrm{H} 2)$ that reciprocal emotional ties will be more likely among family members sharing common testing-status.

\section{[[Table 2 About Here]]}

We find support for our third hypothesis that the number of shared partners increases the propensity for emotional support ties. This is indicated for exogenous shared partners $(\mathrm{H} 3 \mathrm{a})$ by the significantly positive coefficient for the respective exogenous shared partners covariate term $(b=1.0701, p<0.001)$. Moreover, the endogenous shared partners $(\mathrm{H} 3 \mathrm{~b})$ distribution-modeled here by the geometrically weighted shared partners distribution term is significant and positive $(b=1.4270, p<0.001)$, suggesting that adding a single edge to the model increases the number of triangles closed transitively. Therefore, we conclude that family members who share a large number of shared supports outside and inside the observed family network are likely to be supportive of one another.

Our fourth hypothesis, that family members who seek support from outside the observed family network will be less likely to receive $(\mathrm{H} 4 \mathrm{a})$, and more likely to send $(\mathrm{H} 4 \mathrm{~b})$, emotional support ties within the family, is fully supported by our results. We find that as the main effects of the number of both socially and biologically related unique exogenous supporters (NUES) increases, the propensity for in-ties declines $(b=-0.3996$, $p<0.05$ and $b=-0.4771, p<0.01)$. The propensity for out-ties increases as the socially related NUES that network member has goes up $(b=0.4926, p<0.001)$. The coefficient for biologically related NUES is not significant, net of other factors. This suggests that individuals with greater number of exogenous supporters may not be seen by others within the family as needing (or themselves as seeking) emotional support. At the same time, they may also be seen as a well of emotional support for others, as they are relied upon to send more supportive ties, especially if they are connected to greater numbers of socially connected supporters that are not otherwise connected to their respective family members. Moreover, there is a single significant interaction effect between the overall sociality of receivers and the effect of socially related NUES on their out-ties, such that test receivers with larger number of NUES become less likely to be incident on ties in general and in particular have fewer out-ties $(b=-0.3040, p<0.01)$. That is, the positive effects of socially related NUES on out-ties is likely the result of only test decliners (and not test receivers or others) sending more ties as the number of their unique exogenous socially related emotional supporters goes up. Thus, we also find 
partial support for our final hypothesis (H5) that the effect of having a greater number of unique exogenous support partners depends on the testing-status of the individuals involved in those ties, though this evidence is weak at best with only a single significant effect.

Finally, we report several findings from the covariates included in the model either because they were thought to be related to emotional support tie formation mechanisms (i.e., gender homophily, age differences) or enter into the model as controls on the margins of other effects (i.e, edges, geometrically weighted in- and out- degree distributions, sociality, twopaths). Both test receivers and test decliners tend to be incident on fewer emotional support ties than other family members who were either not-at-risk, passively declined, or were not otherwise offered genetic testing as indicated by the significant negative coefficients for sociality associated with those effects ($0.8736, p<0.05$ and $-1.6538, p<0.001$ ). The larger positive effects for geometrically weighted in- and out- degree distributions suggest lower likelihood of sending and receiving emotional support ties to and from higher degree actors as more ties form in the network $(b=2.2110, p<0.01 ; b=1.3561, p<0.05)$. There were no significant age or gender effects.

\section{Discussion}

Communal coping has long been considered a family-level process whereby individuals collectively assess, and rise to the challenge of adapting to, a shared threat (Afifi et al., 2006; Berg et al., 1998). When such a threat takes the form of a heritable cancer syndrome, family members emotionally support each other as part of their adaptive process. While the theoretical underpinnings of communal coping are relational, few studies before this have modeled communal coping mechanisms across several families with relational statistics that map directly to hypothesized social network processes. The current report represents a substantial step forward in the direction of general research on communal coping as well as specific research on familial adaptation to genetic risk of disease.

\section{Communal coping in families at risk of LS}

Our results reveal that the testing-status of individual family members is marginally associated with the formation of support ties. While reciprocity overall was at play in the emotional support exchange within these networks, it was actually suppressed between two individuals with the same testing-status, all else constant. Family members who did not share biological risk for inheriting LS, and thus not offered testing, were involved in more emotional support ties than those at risk. Together, these results strongly 
implicate the importance of those members not-at-risk of LS in familial communal coping.

Our results also demonstrate that the flow of emotional support resources is not limited to the bounds of the family. Indeed, network members from outside the family system are an important coping resource. These exogenous ties (31\% of which represent nonbiological relations), impact relationships within the network too by increasing the propensity to send emotional support and decreasing reliance within the family network for one's own support. Individuals with more outside resources may be seen by family members as having increased socioemotional capital, and thus good sources of support. Perhaps this is a manifestation of group size buffering effects (Stiller \& Dunbar, 2007), which potentially explains why we see a positive testing-status heterophily effect within the family. Moreover, when such outside sources of support are shared between two family members, they are very likely to support one another. Thus, both the number of unique exogenous supporters and the number of shared exogenous supporters diffuse into the family network and reinforce endogenous emotional support ties.

\section{Communal coping as a network process}

Not only do our results improve our understanding of the long-term patterns of emotional support exchange in families coping with increased cancer risk, but they also illustrate how social network approaches can be used to test structural hypotheses related to communal coping. The majority of previous work guided by communal coping either aggregates structural exchanges to the individual (Koehly et al., 2008), is limited to dyadic interactions (Zajdel et al., 2018), or uses qualitative approaches to gain a deeper understanding of group member motivations (Afifi et al., 2006). While each of these approaches contributes to our understanding of communal coping processes, the current research is unique because we consider structural exchanges within a broader system. In so doing, we have defined several network processes that align with communal coping theory.

Of note, we focused on established patterns of emotional support exchange among family members at least 3 years following the identification of a LS-associated mutation within the family. Coping is a process that may occur in stages, with expected fluctuations in support exchanges during critical events (Afifi et al., 2012; Cohen \& Lazarus, 1973). As such, investigation of this process as family members make decisions about genetic services, disclose results or disease diagnoses, and engage in screening behaviors, will require study designs that capture such interpersonal exchanges as they occur. While we don't have the data to investigate such effects, this paper is a first-step in characterizing theoretically what communal coping might look like structurally within networks and can easily be expanded to investigate structural shifts 
during critical events. For example, we might hypothesize increased tendencies in information exchange immediately following genetic testing results disclosure or engagement in cancer screening, or mobilization of emotional support resources and tangible aid following disease diagnosis and treatment activities.

Families affected by inherited conditions like LS are often simultaneously negotiating two social trajectories characterizing the illness career (Koehly, 2017). As such, family members are coping with multiple stressors, whether, for example, worry associated with their own or others' cancer risk or burden related disease diagnoses and treatment. Support resources aimed at addressing these stressors either directly or indirectly may take on a variety of forms, including multiplexity in support roles (Koehly \& Marcum, 2018). However, given that our results suggest potential for limited capacity based on support demands, we might hypothesize that families coping with such multiple stressors are more likely to exhibit exogenous emotional support ties, freeing up capacity for exchange of information and tangible assistance within the family network. Multivariate network analyses that can model this multiplexity are needed to move this work forward.

\section{Limitations}

While this study provides considerable insight into how communal coping mechanisms may operate vis-a-vis the social network processes, we would be remiss without discussing its limitations. First, only six families from the original dataset had participants with enough testing-status heterogeneity to evaluate our hypotheses using the ERGM approach. It's possible that these families are unique in their communal coping strategy. Despite such a small number of families, most network studies analyze relationships in a single network: here, using recent developments in ERGM, we were able to pool information from multiple networks to bolster our inferences. Second, in order to model the proposed structural hypotheses, the six families considered here are those most successful in referring members into study. Thus, these results likely represent families effectively coping collectively and, as such, represent a model system to illustrate a structural approach to communal coping. Future work, however, should consider study designs that provide opportunity to test more directly the dynamics of communal coping processes as they unfold in networks over time using longitudinal network data. We also recognize that our choice of modelling the networks together represents a limitation in that we cannot make inferences from the parameter estimates to the individual family-level effects and instead chose to keep our inferences at the general process level overall. Future efforts with multi-family network dataset with sufficient numbers can consider the random-effects hierarchical ERGM model of Slaughter \& Koehly (2016) to evaluate family-level factors that may affect the structure of communal coping. Due to our sample limitations, we could not leverage such 
developments in hierarchical network modeling. Finally, while LS is an ideal model system for investigating the communal coping mechanisms we've detailed here, the results may not be generalizable to other contexts wherein families are coping with different shared stressors. Future comparative research is warranted to further our understanding of those structural features that characterize communal coping processes across contexts.

\section{Conclusion}

Promisingly, though, clinical genetic services are increasingly common as the landscape of cancer, and other genetic syndromes is in a phase of rapid discovery. Moreover, direct-to-consumer personal genomic services is increasingly accessible to families looking for both ancestral and health information contained in their DNA. Taken together, these developments will continue to contextualize the issue of how families with a mixture of genetic test receivers and genetic test decliners interact with one another. It is almost certain that the use of these services will reveal a collective stressor hidden in DNA for some families - be it disease conferring mutations, errors of paternity, or discrepancies in the family ancestral knowledge. Our focus on LS may provide clues about how these more general stressors are collectively assessed and coped with in families who have some members who choose to seek out such information and some who seek to avoid it.

\section{References}

Afifi, TD. (2015). Communal Coping. The International Encyclopedia of Interpersonal Communication (1-5). John Wiley \& Sons. doi: 10.1002/9781118540190.wbeic049

Afifi, WA, Felix, E.D., \& Afifi, T.D. (2012). The impact of uncertainty and communal coping on mental health following natural disasters. Anxiety, Stress \& Coping, 25(3), 329-347. doi: 10.1080/10615806.2011.603048

Afifi, T.D., Hutchinson, S., \& Krouse, S. (2006). Toward a theoretical model of communal coping in postdivorce families and other naturally occurring groups. Communication Theory, 16(3), 378-409.

Aktan-Collan, K.I., Kääriäinen, H.A., Kolttola, E.M., Pylvänäinen, K., Järvinen, H.J., Haukkala, A.H., \& Mecklin, J.P. (2011). Sharing genetic risk with next generation: Mutation-positive parents' communication with their offspring in Lynch Syndrome. Fam Cancer, 10(1), 43-50. doi:10.1007/s10689-010-9386-x 
Aktan-Collan, K., Mecklin, J.P., Jarvinen, H., Nystrom-Lahti, M., Peltomaki, P., Soderling, I., ... Kaariainen, H. (2000). Predictive genetic testing for hereditary nonpolyposis colorectal cancer: uptake and long-term satisfaction. Int J Cancer, 89(1), 4450.

Antonucci, T.C., \& Jackson, J.S. (1990). The role of reciprocity in social support. In B.R. Sarason, I.G. Sarason, \& G.R. Pierce (Eds.), Wiley series on personality processes. Social support: An interactional view (pp. 173-198). Oxford, England: John Wiley.

Ashida, S., Hadley, D.W., Goergen, A.F,, Skapinsky, K.F., Devlin, H., Koehly, L.M. (2011). The importance of older family members in providing social resources and promoting cancer screening in families with a hereditary cancer syndrome. The Gerontologist, 51(6), 833-842. doi:10.1093/geront/gnr049

Bartuma, K., Nilbert, M., \& Carlsson, C. (2012). Family perspectives in Lynch syndrome becoming a family at risk, patterns of communication and influence on relations. Hereditary Cancer in Clinical Practice, 10(1). doi:10.1186/1897-4287-10-6

Berg, C.A., Meegan, S.P., \& Deviney, F.P. (1998). A social-contextual model of coping with everyday problems across the lifespan. International Journal of Behavioral Development, 22(2), 239-261.

Boland, C.R., \& Lynch, H.T. (2013). The history of Lynch syndrome. Familial Cancer, June; 12(2), 145-157. doi:10.1007/s10689-013-9637-8

Burton, A.M., Hovick, S.R., \& Peterson, S.K. (2012). Health behaviors in patients and families with hereditary colorectal cancer. Clinics in Colon and Rectal Surgery, 25(2), 111-117. doi:10.1055/s-0032-1313782

Cohen, M.A., \& Lazarus, R.S. (1973). Active Coping Processes, Coping Dispositions, and Recovery from Surgery. Psychosomatic Medicine, 35(5), 375-389

Douglas, H.A., Hamilton, R.J., \& Grubs, R.E. (2009). The effect of BRCA gene testing on family relationships: a thematic analysis of qualitative interviews. Journal of Genetic Counseling, 18(5), 418-435. doi: 10.1007/s10897-009-9232-1

Eliezer, D., Hadley, D.W., \& Koehly, L.M. (2014). Exploring psychological responses to genetic testing for Lynch syndrome within the family context. Psycho-Oncology, 23(11), 1292-1299. doi:10.1002/pon.3551 
Ersig, A.L., Williams, J.K., Hadley, D.W., Koehly, L.M. (2009). Communication, encouragement, and cancer screening in families with and without mutations for hereditary nonpolyposis colorectal cancer: a pilot study. Genet Med, 11(10), 728-734. doi: 10.1097/GIM.0b013e3181b3f42d

Ersig, A.L., Hadley, D.W., \& Koehly, L.M. (2011). Understanding patterns of health communication in families at risk for hereditary nonpolyposis colorectal cancer: examining the effect of conclusive versus indeterminate genetic test results. Health Communication, 26(7), 587-594.

Gaff, C.L., Collins, V., Symes, T., \& Halliday, J. (2005). Facilitating family communication about predictive genetic testing: probands' perceptions. J Genet Couns, 14(2), 133-140. doi:10.1007/s10897-005-0412-3

Giardiello, F.M., Allen, J.I., Axilbund, J.E., Boland, C.R., Burke, C.A., Burt, R.W., .... Levin, T.R. (2014). Guidelines on genetic evaluation and management of Lynch syndrome: a consensus statement by the US Multi-Society Task Force on Colorectal Cancer. Gastroenterology, 147(2), 502-526.

Gondal, N., \& McLean, P.D. (2013). What makes a network go round? Exploring the structure of a strong component with exponential random graph models. Social Networks, 35(4), 499-513.

Granovetter, M.S. (1973). The strength of weak ties. American Journal of Sociology, 78(6), 1360-1380.

Granovetter, M. (1979). The theory-gap in social network analysis. In P.W. Holland, S. Leinhardt (Eds.), Perspectives on social network research. Academic Press: New York. pp. 501-518.

Gritz, E.R., Peterson, S.K., Vernon, S.W., Marani, S.K., Baile, W.F., Watts, B.G., . . Lynch, P.M. (2005). Psychological impact of genetic testing for hereditary nonpolyposis colorectal cancer. J Clin Oncol, 23(9), 1902-1910. doi:10.1200/jco.2005.07.102

Hadley, D.W., Jenkins, J., Dimond, E., Nakahara, K., Grogan, L., Liewehr, D.J., . . . Kirsch, I. (2003). Genetic counseling and testing in families with hereditary nonpolyposis colorectal cancer. Archives of Internal Medicine, 163(5), 573-582.

doi:10.1001/archinte.163.5.573 
Communal Coping in Lynch Syndrome Families

Handcock, M.S., Hunter, D.R., Butts, C.T., Goodreau, S.M., Krivitsky, P.N., Morris, M., .... Krivitsky, M.P.N. (2017). Package 'ergm' for R. Technical manual. Accessed on 01/04/2017 from: http://mirror.its.sfu.ca/mirror/CRAN/web/packages/ergm/ergm.pdf

Hannum, J.W., Giese-Davis, J., Harding, K., \& Hatfield, A.K. (1991). Effects of individual and marital variables on coping with cancer. Journal of Psychosocial Oncology, 9(2), 120. doi:10.1300/J077v09n02_01

Hirlekar P, Mathur S, Rastogi A, et al. (2016). Yield and costs of routine testing of all newly diagnosed colon cancers for genetic syndromes. [Am J Gastroenterol abstract 148]. Am J Gastroenterol, 112(suppl 1), S71.

House, J.S., Umberson, D., \& Landis, K.R. (1988). Structures and processes of social support. Annual Review of Sociology, 14(1), 293-318.

Ishii, N., Arai, M., Koyama, Y., Ueno, M., Yamaguchi, T., Kazuma, K., Muto, T. (2011). Factors affecting encouragement of relatives among families with Lynch syndrome to seek medical assessment. Fam Cancer, 10(4), 649-654. Doi: 10.1007/s10689-0119462-x

Jasperson, K. W., Tuohy, T. M., Neklason, D. W., \& Burt, R. W. (2010). Hereditary and familial colon cancer. Gastroenterology, 138(6), 2044-2058.

Johnson, D.W. and Johnson, R.T. (2005) New developments in social interdependence theory. Genetic, Social, and General Psychology Monographs, 131(4), 285-358.

Kloor, M., Voigt, A.Y., Schackert, H.K., Schirmacher, P., von Knebel, D.M., Bläker, H. (2011). Analysis of EPCAM protein expression in diagnostics of Lynch syndrome. J Clin Oncol, 29, 223-227. doi: 10.1200/JCO.2010.32.0820

Koehly, L. M. (2017). It's interpersonal: Family relationships, genetic risk, and caregiving. Gerontologist, 57(1), 32-39. doi: 10.1093/geront/gnw103

Koehly, L. M., \& Marcum, C. S. (2018). Multi-Relational Measurement for Latent Construct Networks. Psychological Methods, 23(1), 42-57. doi:10.1037/met0000110

Koehly, L. M., Peters, J. A., Kuhn, N., Hoskins, L., Letocha, A., Kenen, R., .... Greene, M. H. (2008). Sisters in hereditary breast and ovarian cancer families: communal coping, social integration, and psychological well-being. Psycho-Oncology, 17, 812-821. doi: $10.1002 /$ pon. 1373 
Koehly, L.M., Peterson, S. K., Watts, B. G., Kempf, K. K., Vernon, S. W., Gritz, E. R. (2003). A social network analysis of communication about hereditary nonpolyposis colorectal cancer genetic testing and family functioning. Cancer Epidemiol Biomarkers Prev, 12(4), 304-313.

Kuijer, R., Ybema, J., Buunk, B P., de Jong, G.M., Thijs-Boer, F., \& Sanderman, R. (2000). Active engagement, protective buffering, and overprotection: Three ways of giving support by intimate partners of patients with cancer. Journal of Social and Clinical Psychology, 19(2), 256-275. doi: 10.1521/jscp.2000.19.2.256

Lawrence, A.R., \& Schigelone, A.R.S. (2002). Reciprocity beyond dyadic relationships: Aging-related communal coping. Research on Aging, 24(6), 684-704.

Leenan, C.H., Heijer, M., van der Meer, C., Kuipers, E.J., van Leerdam, M.E., Wagner, A. (2016). Genetic testing for Lynch syndrome: family communication and motivation. Fam Cancer, 15(1), 63-73. doi:10.1007/s10689-015-9842-8

Lewis, M.A., McBride, C.M., Pollak, K.I., Puleo, E., Butterfield, R.M., Emmons, K.M. (2006). Understanding health behavior change among couples: an interdependence and communal coping approach. Social Science \& Medicine, 62, 1369-1380. https://doi.org/10.1016/j.socscimed.2005.08.006

Loader, S., Shields, C., Levenkron, J.C., Fishel, R., \& Rowley, P.T. (2002). Patient vs. physician as the target of educational outreach about screening for an inherited susceptibility to colorectal cancer. Genet Test, 6(4), 281-290. doi: $10.1089 / 10906570260471813$

Lynch, H.T., Lynch, P.M., Lanspa, S.J., Snyder, C.L., Lynch, J.F., \& Boland, C.R. (2009). Review of the Lynch syndrome: history, molecular genetics, screening, differential diagnosis, and medicolegal ramifications. Clin Genet, 76(1), 1-18. doi:10.1111/j.1399-0004.2009.01230.x

Lyons, R.F., Mickelson, K.D., Sullivan, M.J., Coyne J.C.. (1998). Coping as a communal process. Journal of Social and Personal Relationships, 15(5), 579-605.

McPherson, M., Smith-Lovin, L., \& Cook, J.M. (2001). Birds of a feather: Homophily in social networks. Annual review of sociology, 27(1), 415-444. 
Mollenhorst, G., Völker, B., \& Flap, H. (2011). Shared contexts and triadic closure in core discussion networks. Social Networks, 33(4), 292-302.

Mesters, I., Ausems, M., Eichhorn, S., \& Vasen, H. (2005). Informing one's family about genetic testing for hereditary non-polyposis colorectal cancer (HNPCC): A retrospective exploratory study. Fam Cancer, 4(2), 163-167. doi:10.1007/s10689-004-7992-1

Palmquist, A.E.L, Koehly, L.M., Peterson, S.K., Shegog, M., Vernon, S.W., Gritz, E.R. (2010). 'The cancer bond': Understanding the formation of cancer risk perception in families with Lynch syndrome. Journal of Genetic Counseling, 19(5), 473-486. doi: 10.1007/s10897-010-9299-8

Pentz, R.D., Peterson, S.K., Watts, B., Vernon, S.W., Lynch, P.M., Koehly, L.M., Gritz, E.R. (2005). HNPCC family members' perceptions about the duty to inform and health professionals' role in the dissemination of genetic information. Genetic Testing, 9(3), 261-268. doi: 10.1089/gte.2005.9.261

Peterson, S.K. (2005). The role of the family in genetic testing: Theoretical perspectives, current knowledge, and future directions. Health Education and Behavior, 32(5), 627639. doi:10.1177/1090198105278751

Power, E. A. (2017). Social support networks and religiosity in rural South India. Nat. Hum. Behav. 1, 0057. doi.org/10.1038/s41562-017-0057

Robins, G., Pattison, P., Kalish, Y., Lusher, D. (2007). An introduction to exponential random graph (p) models for social networks. Social Networks, 29(2), 173-191. doi:10.1016/j.socnet.2006.08.002

Rusbult C., and Lange, P.V. Interdependence processes (1996). In: Kruglanski, A.W., Higgins and E.T., editors. Social Psychology: Handbook of basic principles. New York: Guilford; p.564-596.

Schwarz, S. (2014). The social dimension of coping: communal negotiations of social benefits and burdens. In Cultural Psychology of Coping with Disasters (pp. 203-223). Springer New York.

Sharaf R.N., Myer P, Stave C.D., Diamond L.C., Ladabaum U. (2013). Uptake of genetic testing by relatives of Lynch syndrome probands: a systematic review. Clin Gastroenterol Hepatol, 11(9):1093-100. doi: 10.1016/j.cgh.2013.04.044 
Communal Coping in Lynch Syndrome Families

Slaughter, A. J., \& Koehly, L. M. (2016). Multilevel models for social networks: hierarchical Bayesian approaches to exponential random graph modeling. Social Networks, 44, 334-345.

Stiller, J., \& Dunbar, R.I. (2007). Perspective-taking and memory capacity predict social network size. Social Networks, 29(1), 93-104. doi: 10.1016/j.socnet.2006.04.001

Stoller, E.P. (1985). Exchange patterns in the informal support networks of the elderly: The impact of reciprocity on morale. Journal of Marriage and the Family, 335-342.

Syngal, S., Brand, R.E., Church, J.M., Giardiello, F.M., Hampel, H.L., Burt, R.W. (2015). ACG Clinical Guideline: Genetic testing and management of hereditary gastrointestinal cancer syndromes. The American Journal of Gastroenterology, 110, 223-262. doi: 10.1038/ajg.2014.435

Umar, A., Boland, C.R., Terdimanm, J.P., Syngal, S., de la Chapelle, A., Rüschoff, J., .... Srivastava, S. (2004). Revised Bethesda Guidelines for hereditary nonpolyposis colorectal cancer (Lynch Syndrome) and microsatellite instability. J Natl Cancer Inst. 2004 Feb 18; 96(4), 261-268.

Voorwinden, J.S., \& Jaspers, J.P.C. (2016). Prognostic Factors for Distress After Genetic Testing for Hereditary Cancer. Journal of Genetic Counseling, 25(3), 495-503. doi: 10.1007/s10897-015-9894-9

Watson, P., Vasen, H.F.A., Mecklin, J.P., Bernstein, I., Aarnio, M., Jarvinen, H.J., . . . Lynch, H.T. (2008). The risk of extra-colonic, extra-endometrial cancer in the Lynch syndrome. Int J Cancer, 123(2), 444-449. doi: 10.1002/ijc.23508

Weissman, S.M., Burt, R., Church, J., Erdman, S., Hampel, H., Holter, S., . . Senter, L. (2012). Identification of individuals at risk for Lynch syndrome using targeted evaluations and genetic testing: National Society of Genetic Counselors and the Collaborative Group of the Americas on Inherited Colorectal Cancer joint practice guideline. J Genet Couns, 21(4), 484-493. doi: 10.1007/s10897-011-9465-7

Zajdel, M., Helgeson, V.S., Seltman, H.J., Korytkowski, M.T., \& Hausmann, L.R. (2018). Daily communal coping in couples with type 2 diabetes: Links to mood and self-care. Annals of Behavioral Medicine. doi: 10.1093/abm/kax047 


\section{Tables and Figures}

\begin{tabular}{|c|c|c|c|c|c|c|c|c|}
\hline Statistic & $\begin{array}{c}\text { Family } \\
1\end{array}$ & $\begin{array}{c}\text { Family } \\
2\end{array}$ & \begin{tabular}{|c|} 
Family \\
3
\end{tabular} & $\begin{array}{c}\text { Family } \\
4\end{array}$ & $\begin{array}{c}\text { Family } \\
5\end{array}$ & $\begin{array}{c}\text { Family } \\
6\end{array}$ & Mean & SD \\
\hline $\begin{array}{l}\text { Network Size (number of interviewed } \\
\text { informants) }\end{array}$ & 13.00 & 20.00 & 10.00 & 15.00 & 6.00 & 10.00 & 12.33 & 4.84 \\
\hline $\begin{array}{l}\text { Network Density (among interviewed } \\
\text { informants) }\end{array}$ & 0.17 & 0.15 & 0.14 & 0.21 & 0.20 & 0.17 & 0.17 & 0.03 \\
\hline $\begin{array}{l}\text { Number of Non-Participant Enumerated } \\
\text { Family Members }\end{array}$ & 68.00 & 87.00 & 43.00 & 49.00 & 25.00 & 32.00 & 50.67 & 23.19 \\
\hline $\begin{array}{l}\text { Proportion Non-Participant Biological } \\
\text { Relatives Enumerated }\end{array}$ & 0.85 & 0.80 & 0.63 & 0.49 & 0.74 & 0.61 & 0.69 & 0.13 \\
\hline $\begin{array}{l}\text { Proportion of Endogenous Ties Among } \\
\text { Biological Relatives }\end{array}$ & 0.71 & 0.68 & 1.00 & 0.90 & 1.00 & 0.80 & 0.85 & 0.14 \\
\hline $\begin{array}{l}\text { Average Number of Edgewise } \\
\text { Exogenous Shared Supporters }\end{array}$ & 0.15 & 0.42 & 1.77 & 0.73 & 0.67 & 1.07 & 0.80 & 0.57 \\
\hline $\begin{array}{l}\text { Average Number of Unique Exogenous } \\
\text { Biologically Related Supporters }\end{array}$ & 0.92 & 1.75 & 0.80 & 0.20 & 1.50 & 0.60 & 0.96 & 0.57 \\
\hline $\begin{array}{l}\text { Average Number of Unique Exogenous } \\
\text { Socially Related Supporters }\end{array}$ & 0.54 & 1.40 & 0.90 & 1.47 & 1.67 & 1.20 & 1.20 & 0.41 \\
\hline Proportion Test Receivers & 0.47 & 0.30 & 0.50 & 0.53 & 0.50 & 0.50 & 0.47 & 0.08 \\
\hline Proportion Test Decliners & 0.15 & 0.10 & 0.30 & 0.20 & 0.33 & 0.20 & 0.21 & 0.09 \\
\hline Proportion Not at Risk & 0.38 & 0.60 & 0.20 & 0.27 & 0.17 & 0.30 & 0.32 & 0.16 \\
\hline Support Tie Reciprocity & 0.62 & 0.61 & 0.62 & 0.64 & 0.67 & 0.67 & 0.64 & 0.03 \\
\hline Proportion Male & 0.25 & 0.40 & 0.30 & 0.47 & 0.17 & 0.50 & 0.35 & 0.13 \\
\hline
\end{tabular}

Table 1. Network Descriptive Statistics 


\begin{tabular}{|c|c|c|c|}
\hline Model Term & Beta & SE & p-value \\
\hline \multicolumn{4}{|l|}{ Hypothesis 1} \\
\hline Receiver $\rightarrow>$ Receiver Mixing (ref=other mixing) & 1.6608 & 0.6651 & $0.0125 *$ \\
\hline Decliner $\rightarrow>$ Receiver Mixing (ref=other mixing) & 1.7533 & 0.6462 & $0.0067^{* *}$ \\
\hline Receiver $\rightarrow>$ Decliner Mixing (ref=other mixing) & 0.5012 & 0.6787 & 0.4602 \\
\hline Decliner $\rightarrow$ Decliner Mixing (ref=other mixing) & 2.5289 & 0.8869 & $0.0044^{* *}$ \\
\hline \multicolumn{4}{|l|}{ Hypothesis 2} \\
\hline Homophilous Reciprocity & -2.2789 & 0.6980 & $0.0011 * *$ \\
\hline Baseline Reciprocity & 2.5840 & 0.5938 & $0.0001^{* * *}$ \\
\hline \multicolumn{4}{|l|}{ Hypothesis 3} \\
\hline Edgewise Exogenous Shared Partners & 1.0701 & 0.1800 & $0.0001^{* * *}$ \\
\hline GW Edgewise Shared Partners Distribution (alpha=0.85) & 1.4270 & 0.1616 & $0.0001^{* * *}$ \\
\hline \multicolumn{4}{|l|}{ Hypothesis 4} \\
\hline In-tie effect of Socially Related NUES & -0.3996 & 0.1750 & $0.0224 *$ \\
\hline Out-tie effect of Socially Related NUES & 0.4926 & 0.1227 & $0.0001^{* * *}$ \\
\hline In-tie effect of Biologically Related NUES & -0.4771 & 0.1807 & $0.0083^{* *}$ \\
\hline Out-tie effect of Biologically Related NUES & -0.0096 & 0.0903 & 0.9155 \\
\hline \multicolumn{4}{|l|}{ Hypothesis 5} \\
\hline Sociality of Receivers X In-tie effect of Socially Related NUES & 0.0760 & 0.1388 & 0.5841 \\
\hline Sociality of Decliners X In-tie effect of Socially Related NUES & -0.0333 & 0.1793 & 0.8525 \\
\hline Sociality of Receivers X Out-tie effect of Socially Related NUES & -0.3040 & 0.1120 & $0.0066 * *$ \\
\hline Sociality of Decliners X Out-tie effect of Socially Related NUES & 0.0905 & 0.1269 & 0.4757 \\
\hline Sociality of Receivers X In-tie effect of Biologically Related NUES & 0.1431 & 0.1567 & 0.3611 \\
\hline Sociality of Decliners X In-tie effect of Biologically Related NUES & 0.0869 & 0.1672 & 0.6032 \\
\hline Sociality of Receivers X Out-tie effect of Biologically Related NUES & -0.0346 & 0.0960 & 0.7188 \\
\hline Sociality of Decliners X Out-tie effect of Biologically Related NUES & 0.0619 & 0.1293 & 0.6320 \\
\hline \multicolumn{4}{|l|}{ Covariates } \\
\hline Edges & -3.7672 & 0.8095 & $0.0001^{* * *}$ \\
\hline Sociality of Receivers (ref=others) & -0.8736 & 0.3789 & $0.0211 *$ \\
\hline Sociality of Decliners (ref=others) & -1.6538 & 0.4804 & $0.0006^{* * *}$ \\
\hline Sociality of Males (ref=females) & -0.2726 & 0.1705 & 0.1099 \\
\hline Absolute Difference in Age & -0.0008 & 0.0067 & 0.9021 \\
\hline Gender Homophily (ref=heterophily) & -0.4306 & 0.2413 & 0.0744 \\
\hline GW Indegree Distribution (alpha=0.97) & 2.2110 & 0.7373 & $0.0027^{* *}$ \\
\hline GW Outdegree Distribution (alpha=0.42) & 1.3561 & 0.5790 & $0.0192 *$ \\
\hline Twopath & -0.1462 & 0.0835 & 0.0798 \\
\hline
\end{tabular}

Null Deviance: 1325 on 956 degrees of freedom

Residual Deviance: 454 on 927 degrees of freedom

AIC: 512 BIC: 653

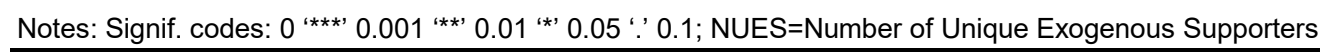

$\mathrm{GW}=$ Geometrically weighted

Table 2. Results of Family-Block Diagonal Constrained Exponential Random Graph Model 
A
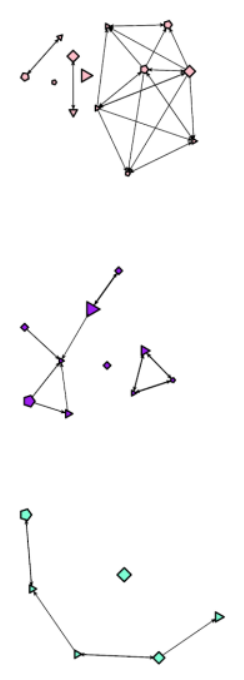
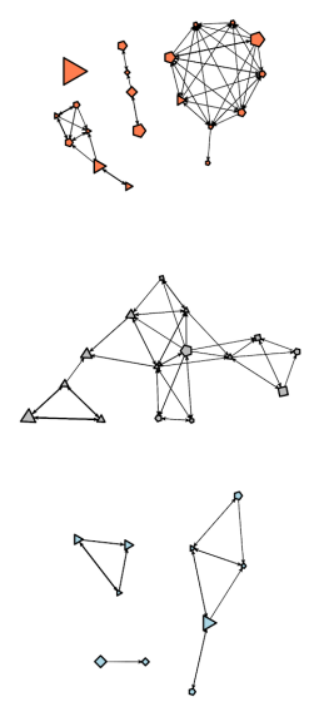

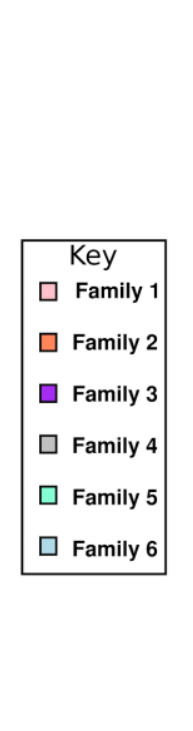

Figure 1. Emotional Support Networks in Six Families Affected by Lynch Syndrome. Panel A projects each of the six family networks using the Fructerman-Reingold forcedirected graph layout algorithm. The shapes of nodes indicate testing status (triangles=test receivers, squares=test decliners, pentagons=not-at-risk). The size of each node is scaled in proportion to the number of exogenous support partners that family member informants reported and the width of each edge is scaled in proportion to the number of exogenous supporters each pair of family informants with an edge share. Panel $B$ is a graphical representation of how the data are structured for the pooled likelihood Exponential Random Graph Model with a block-diagonal constraint limiting estimation to only ties within, and not between, families. Each family member (vertex) is indexed along the rows and columns. Colored blocks indicate co-membership within a family and black cells within those blocks indicate the presence of an edge between two family members. White, "off-diagonal" cells indicate impossible ties. 